\title{
A High Precision Laue Technique for Crystal Orientation
}

\author{
Mathiesen, S. Ipsen
}

Published in:

Review of Scientific Instruments

Link to article, DOI:

$10.1063 / 1.1683238$

Publication date:

1968

Document Version

Publisher's PDF, also known as Version of record

Link back to DTU Orbit

Citation (APA):

Mathiesen, S. I. (1968). A High Precision Laue Technique for Crystal Orientation. Review of Scientific Instruments, 39(11), 1771-1772. https://doi.org/10.1063/1.1683238

\section{General rights}

Copyright and moral rights for the publications made accessible in the public portal are retained by the authors and/or other copyright owners and it is a condition of accessing publications that users recognise and abide by the legal requirements associated with these rights.

- Users may download and print one copy of any publication from the public portal for the purpose of private study or research.

- You may not further distribute the material or use it for any profit-making activity or commercial gain

- You may freely distribute the URL identifying the publication in the public portal

If you believe that this document breaches copyright please contact us providing details, and we will remove access to the work immediately and investigate your claim 
tion grating quickly attenuated leaving a sinusoid having the fundamental wave length of the original grating.

For the aluminum oxide surface the difficulty lies in obtaining a chemical etchant which is compatible with KTFR. The available chemical etchants for aluminum oxide $^{2}$ require the etching process to be carried out at elevated temperatures. In our technique an intermediate step was included to produce a mask which is compatible with a chemical etchant for aluminum oxide.

A thin film of chromium metal was first vapor deposited on the aluminum oxide surface. The photoetching technique, similar to that used by Maiya and Blakely, ${ }^{1}$ was then applied to produce the grating in the chromium layer exposing the aluminum oxide. The chromium etchant was a solution of $9.1 \mathrm{wt} . \% \mathrm{KOH}$ and $18.2 \mathrm{wt} . \% \mathrm{~K}_{3} \mathrm{Fe}(\mathrm{CN})_{6}$ as recommended by Kodak. This procedure produced a satisfactory mask of chromium for the etching of aluminum oxide, provided the vapor deposition of chromium is carried out with the aluminum oxide crystal maintained at approximately $500^{\circ} \mathrm{C}$ to ensure good adherence. ${ }^{3}$ Waterfree molten $\mathrm{KOH}$ was used as the etchant for aluminum oxide. Any chromium remaining after the aluminum oxide etching was removed with the chromium etchant. Vacuum annealing was then carried out to produce the desired sinusoidal profile as described by Maiya and Blakely.

Figure 1 shows an interference micrograph of an aluminum oxide surface after $\mathrm{KOH}$ etching. The thickness of the chromium mask used was $0.1 \mu$, and the etching time was $2 \mathrm{~min}$. Figure 2 shows the interference micrograph of the same sample after vacuum anneal for $100 \mathrm{~h}$ at $1800^{\circ} \mathrm{C}$ with vacuum less than $10^{-\mathrm{s}}$ Torr.

We believe that this chemical method provides an alternative to ion bombardment or rf sputtering etching ${ }^{4}$ for aluminum oxide. In the application of the latter two techniques, a choice of proper masking is also difficult, as aluminum oxide has a relatively low etching rate. The sinusoidal profile produced can be used in the experiment for surface energy and surface diffusion coefficient measure-

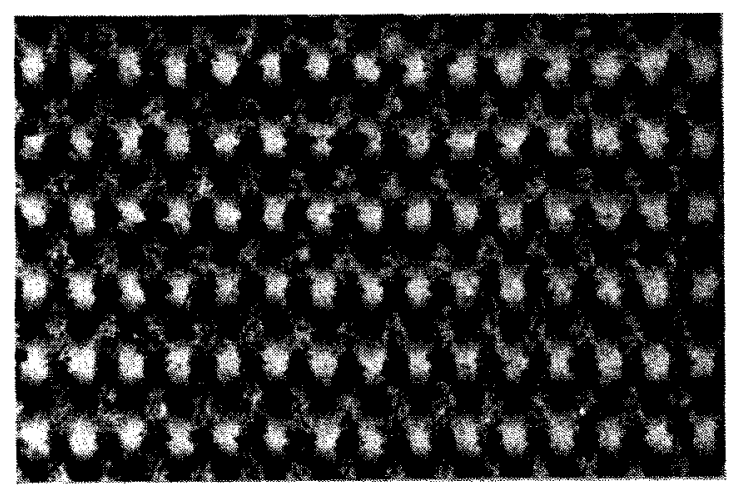

FIG. 1. Interference micrograph of diffraction grating $(\lambda=7.9 \mu)$ etched in single crystal $\mathrm{Al}_{2} \mathrm{O}_{3}$ surface. Depth of step is approximately $0.1 \mu$. One fringe is a change of $0.27 \mu$ in depth.

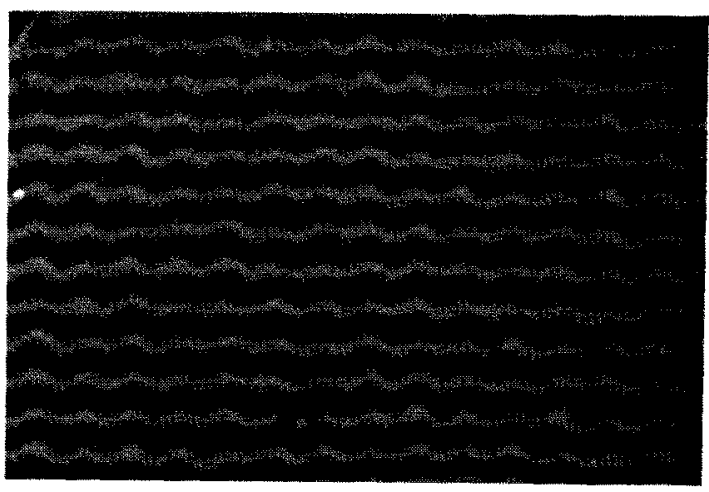

Fra. 2. Interference micrograph of grating after annealing. The profile of the grating is now a sinusoid.

ments by the mass transport technique. The experiment is in progress in this laboratory.

This work was supported by The Advanced Research Projects Agency through The Materials Science Center, Cornell University. We would also like to thank David L. Olson for many helpful discussions.

1 P. S. Maiya and J. M. Blakely, Appl. Phys. Letters 7, 60 (1965). "V. D. Frenchette, "Microstructure of Ceramic Materials," in Proceedings of an American Ceramic Society Sympositum, Pittsburgh, Pa. April 27-28, 1963 (U. S. Dept. of Commerce, National Bureau of Standards, Washington, D. C., 1964), Misc. Publ. No. 257.

${ }^{3}$ M. M. Karnowsky and W. B. Estill, Rev. Sci. Instr. 35, 1324 (1964).

${ }^{4}$ R. T. C. Tsui, Second Symposium of Deposition of Thin Films by Sputtering, University of Rochester, Rochester, New York, June 1967 (Consolidated Vacuum Corporation, Rochester, N. Y., 1967).

\section{A High Precision Laue Technique for Crystal Orientation}

\author{
S. IPSEN MATHESEN \\ Physics Laboratory III, Technical Unicersity of \\ Denmark, Lyngby, Denmark
}

(Received 1 March 1968; and in final form; 16 July 1968)

TN orienting a single crystal by the Laue back reflection method the problem often is to bring a crystallographic symmetry axis parallel to the primary $x$-ray beam. This can be done with high precision by the use of characteristic line spots. If a point in the reciprocal lattice happens to be at, or very close to, the sphere of diffraction corresponding to a wavelength occuring in the characteristic spectrum from the $x$-ray tube, then the corresponding diffracted beam will appear on the photograph with greatly increased intensity compared to the average. Provided the actual symmetry axis does not deviate more than a few degrees from the normal to the irradiated crystal surface 

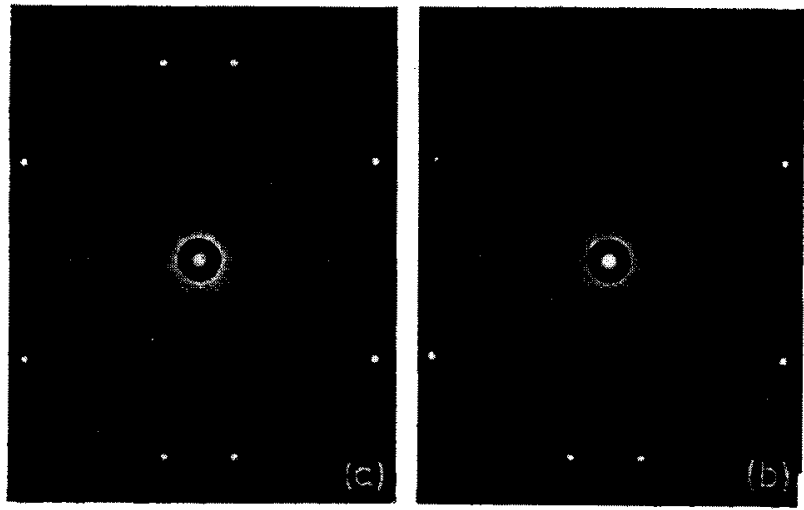

FIg. 1. Laue photographs of a silicon crystal (Mo radiation, $50 \mathrm{kV}$, $10 \mathrm{~mA})$. Irradiated crystal surface nearly parallel to a $\{110\}$ plane. Distance between crystal surface and film $3 \mathrm{~cm}$ (Polaroid film). Exposure time, $1 \mathrm{~min}$. (a) Crystal properly oriented with the $\langle 110\rangle$ axis parallel to the primary beam. (b) $\langle 110\rangle$ axis tilted $0.1^{\circ}$ away from the primary beam.

and the applied collimator has rotational symmetry, the criterion for correct orientation is that the characteristic line spots related by symmetry should appear with the same intensity. This gives a very accurate check on the orientation as is illustrated in Fig. 1 showing Laue photographs of a silicon crystal taken with $50 \mathrm{kV}$ Mo radiation. The irradiated crystal surface was nearly parallel to a $\{110\}$ plane. In taking the picture of Fig. 1(a) the twofold $\langle 110\rangle$ axis was properly oriented parallel to the primary beam as is evident from the equality of intensities of the symmetry related, dense, characteristic line spots. In taking the picture of Fig. 1(b) the orientation was changed $0.1^{\circ}$ resulting in a marked change of the intensities of the dense spots. The requirement of diffraction of characteristic radiation to take place is not too restrictive when one considers the possibility of choosing a proper anode material and using a proper distance between crystal and film. In favorable cases it has been found that deviations less than $0.01^{\circ}$ from a symmetry axis can be detected.

\section{Ion Cyclotron Resonance Detection Using Electron Energy Modulation}

\author{
Jay M. S. Henis and Willitam Frasure \\ Monsanto Company Centrat Research Department, \\ St. Louis, Missouri 63160 \\ (Received 14 June 1968)
}

ON cyclotron resonance has been used recently to study ion molecule reactions at low kinetic energies. The experimental apparatus and techniques have been de- scribed by several authors. ${ }^{1-4}$ Single and double resonance spectra have been obtained by modulating one of the parameters affecting energy absorption. Magnetic field modulation, ${ }^{3,4}$ source drift modulation, ${ }^{4}$ and double resonance frequency modulation ${ }^{2}$ have been commonly used.

Electron energy modulation has not been used but has several useful features which are discussed here. Figure 1 is a typical ionization efficiency curve for a positive ion produced by electron impact. Increasing the electron energy (between 0 and $100 \mathrm{eV}$ ) increases the number of positive ions produced in most chemical systems. Modulation of the electron energy at a desirable fixed frequency causes a repetitive change in the number of ions passing through the detector region of the ICR spectrometer. ${ }^{1,4}$ When an ion is in resonance, the change in number density causes a corresponding change in the level of the marginal oscillator and this may be phase detected in a straightforward manner. Sweeping the magnetic field brings each ion present into resonance. A mass spectrum is thus obtained which is a difference spectrum determined by the values of $E_{b}$ and $E^{\prime}$ in Fig. 1, and the shape of the ionization efficiency curve for each ion.

The ICR spectrometer electron energy circuit provides only direct potential. To accomplish electron energy modulation, auxiliary electronics, consisting of a pulse generator and a pulse amplifier that adds a voltage pulse to a dc base voltage, are necessary. The pulse amplifier described in Fig. 2 may be switched in and out, permitting other modulation schemes to be used without difficulty.

The reference waveform input can be provided by any suitable commercial generator. The amplifier (Fig. 2) is wideband from dc to $3 \mu \mathrm{sec}$ risetime. The pulse feeds

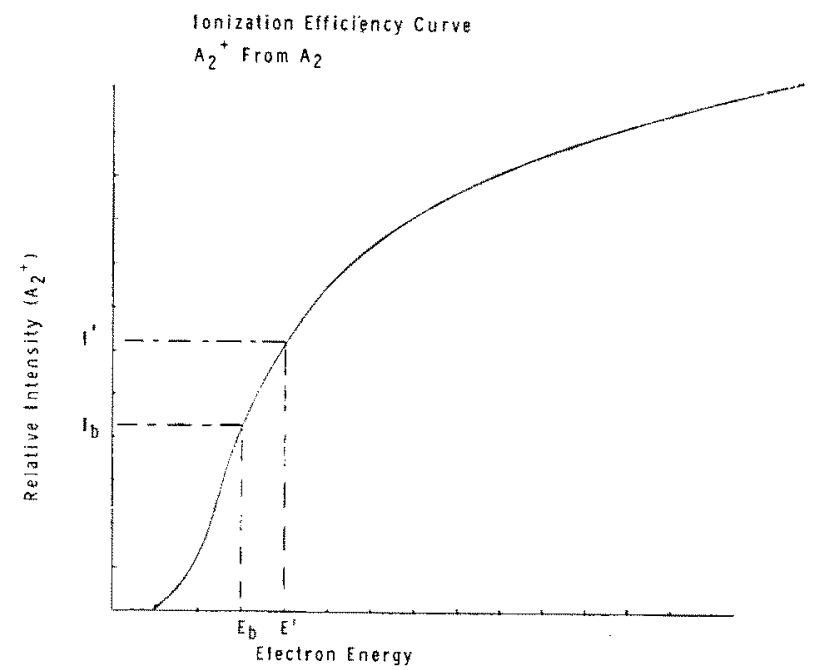

Frg. 1. Typical ionization efficiency curve for a positive ion produced by electron impact. $E_{b}$ is the base electron energy and $E^{\prime}$ is the electron energy during the on phase of the voltage pulse. $I_{b}$ is the ion current at $\mathrm{E}_{\mathrm{b}}$ and $\mathrm{I}$ is the ion current at $\mathrm{E}^{\prime} . \Delta \mathrm{E}$ is $\mathrm{E}^{\prime}-\mathrm{E}_{\mathrm{b}}$. 